\title{
BMJ Open Psychometric testing of a short-form questionnaire for the measurement of health experiences among people with musculoskeletal disorders undergoing multimodal rehabilitation
}

\author{
Birgitta Wiitavaara, ${ }^{\oplus 1}$ Dag Rissén, ${ }^{2}$ Hans Högberg, ${ }^{3}$ Annika Nilsson ${ }^{3,4}$
}

To cite: Wiitavaara B, Rissén $\mathrm{D}$, Högberg $\mathrm{H}$, et al. Psychometric testing of a short-form questionnaire for the measurement of health experiences among people with musculoskeletal disorders undergoing multimodal rehabilitation. BMJ Open 2019;9:e025103. doi:10.1136/ bmjopen-2018-025103

- Prepublication history for this paper is available online. To view these files, please visit the journal online (http://dx.doi. org/10.1136/bmjopen-2018025103).

Received 29 June 2018 Revised 23 November 2018 Accepted 1 April 2019
Check for updates

(C) Author(s) (or their employer(s)) 2019. Re-use permitted under CC BY-NC. No commercial re-use. See rights and permissions. Published by BMJ.

For numbered affiliations see end of article.

Correspondence to Dr. Birgitta Wiitavaara; biawia@hig.se

\section{ABSTRACT}

Aim The aim of the present study was to assess if a previously suggested short-form questionnaire tested among women with non-specific neck-shoulder pain is suitable also for use among men and women with nonspecific musculoskeletal disorders in any part of the body, by testing its construct validity by a confirmatory factor analysis. If not, the secondary aim was to investigate the evolving factor structure when performing an explorative factor analysis of data in the expanded sample.

Methods Questionnaire data were collected in three different contexts, in primary care via eight different multimodal rehabilitation teams and in specialised care via two different specialist care centres. The sample consisted of 116 men $(n=29)$ and women $(n=87)$ with non-specific musculoskeletal disorders. Data were analysed using confirmatory and exploratory factor analysis and a visual comparison between the result of the principal component analysis in the present study and the results attained in a previous study with a similar aim and design.

Results The confirmatory factor analyses did not end up in a model with acceptable measures for validity. Three models were tested, none of them met the criterion for an acceptable model, and the goodness-of-fit statistics were not fully acceptable. The exploratory factor analysis had only partly comparable result compared with previous study.

Conclusion The results of the present study did not prove the suggested short-form questionnaire to be suitable for evaluation of symptoms among men and women with non-specific musculoskeletal disorders in any part of the body. Further studies including larger samples are recommended.

Trial registration number 92199001.

\section{INTRODUCTION}

Musculoskeletal disorders (MSDs) are common and often lead to disability and long-term absenteeism with negative consequences for both the individual and the society. ${ }^{12}$ MSDs are considered to have a multifactorial aetiology involving physical, psychosocial and personal risk factors, ${ }^{3}$ and
Strengths and limitations of this study

- This study included men and women with non-specific musculoskeletal disorders in any part of the body, participating in multimodal rehabilitation in primary care and at specialist centres.

- Relevant biopsychosocial aspects that often are affected for a person with musculoskeletal disorders were considered when constructing a short-form questionnaire.

- Internationally recommended outcome measures were chosen and psychometrically tested.

- A rather small sample posed difficulties in the psychometric testing of the included questionnaires.

accordingly multidimensional treatments based on the biopsychosocial model that takes biological, psychological and social factors into account are recommended. ${ }^{4-7}$ A multitude of instruments are available to evaluate treatments; however, there is a lack of consensus regarding which of them to use and how to combine them. ${ }^{8}$ This lack of consensus reduces the possibilities for comparisons of treatment results, which in turn may hinder the development of treatment methods. Another limitation is that a selection of outcome measures often is used, which do not capture the entire specific spectrum of symptoms the persons suffer from. ${ }^{9}$

We have previously performed a study on women with non-specific MSDs in neck-shoulders, where the intention was to initiate the development of a clinically useful short-form questionnaire. ${ }^{10}$ The study was based on measures recommended from The Initiative on Methods, Measurement and Pain Assessment in Clinical Trials (IMMPACT), which conducts ongoing international developmental work regarding treatments for pain and outcome evaluations in the field of 
clinical pain studies. ${ }^{11}$ Three questionnaires including 61 items were used and a factor analysis resulted in a 9-factor solution including 29 items. These items were derived from three of the four core domains recommended by IMMPACT: pain intensity, emotional functioning and physical functioning. ${ }^{11}$

Studying the usefulness of internationally recommended outcome measures in relation to MSDs can make a valuable contribution to increase the uniformity of outcome measures and thus increase comparability between studies. ${ }^{11}$ Access to specific outcome measures in a clinically useful format may increase the possibility of targeted interventions in terms of prevention and early treatment. In the present study, we want to test if the results from the previous study also are valid among a broader pain population including men and women with non-specific MSDs in any part of the body.

Accordingly, the aim of the present study was to assess if the short-form questionnaire is suitable for use among men and women with non-specific MSDs in any part of the body, by testing its construct validity by a confirmatory factor analysis (CFA). If not, the secondary aim was to investigate the evolving factor structure when performing an explorative factor analysis of data in the expanded sample.

\section{METHODS}

\section{Design}

This is an instrument validation study using confirmatory and exploratory factor analysis of data from patients with non-specific MSDs in any part of the body, which were undergoing multidimensional rehabilitation in either primary or specialised care.

\section{Sample and data collection}

Data were collected in primary care via eight different multimodal rehabilitation teams and in specialised care via two different specialist care centres. The rehabilitation team distributed and collected questionnaires from those participants in the rehabilitation programme that were willing to participate in this study. All patients had been remitted to multimodal rehabilitation by their primary care physicians. Indications for multimodal rehabilitation were persistent or intermittent pain for at least 3 months; pain with a high degree affects the patients' daily life; a patient who have the potential for active change, despite pain; no comorbidity or other condition that will hinder participation in the rehabilitation programme. ${ }^{12}$

\section{Measures}

As in our previous study on the subject, ${ }^{10}$ we considered the recommended ${ }^{13}$ four core domains to include in clinical trials: (1) pain intensity; (2) physical functioning; (3) emotional functioning and (4) general improvement. However, general improvement can only be evaluated after treatment and was therefore excluded as data were obtained once. The outcome measures that are recommended for the remaining three domains are (1) a Numeric Rating Scale (NRS), (2) the Brief Pain Inventory $(\mathrm{BPI})^{14}$ or the Multidimensional Pain Inventory (MPI) ${ }^{15}$ and (3) the Beck Depression Inventory (BDI) $)^{1617}$ or the Profile of Mood States (POMS) ${ }^{18}$ For details on the selected outcome measures, see below.

\section{Pain intensity and physical functioning}

The MPI-Swedish version (MPI-S) ${ }^{19}$ that was selected includes two sections and a total of 34 items. Section 1 (22 items) consists of five subscales: pain severity, interference, life control, affective distress and support. Section 2 (12 items) consists of three subscales regarding responses from significant others: punishing, solicitous and distracting responses, where each included item has a 7-point response scale between 0 (no, not at all) and 6 (yes, very much). Question number 6 in part 1 has to be recoded in reverse to correspond to the scaling of all other questions. MPI-S was also chosen for the assessment of pain intensity, as it includes an NRS to measure pain intensity in two different temporal time perspectives.

\section{Emotional functioning}

Regarding negative emotional functioning, an alternative questionnaire compared with those recommended was chosen. Comparing the content of BDI and POMS, BDI was judged to be the most suitable for this sample. However, the final, alternative choice fell on the Montgomery-Åsberg Depression Scale (MADRS-S). ${ }^{20}$ It has the same qualities as the BDI with respect to its ability to differentiate between different diagnoses and sensitivity to change,${ }^{21}$ and MADRS-S was considered a favourable choice since it can be used free of charge. When answering MADRS-S, people rate their last 3 days' core symptoms of depression in nine items (mood, anxiety, sleep, appetite, ability to concentrate, ability of initiative, emotional commitment, pessimism and vitality). Items are scored from 0 (none at all) to 6 (maximum), with a maximum total score of 54 . Reduction in score reflects symptom improvement.

Depression scales are normally used for the measurement of emotional functioning. However, positive aspects of psychological health have been actualised and also linked to biological processes and biomarkers. ${ }^{22-25}$ Enjoyment of life and emotional well-being have been appraised as the most important aspects of health among people with chronic pain, in addition to pain reduction. ${ }^{26}$ Psychological well-being, rather than specific somatic symptoms, has also been found to influence people's care-seeking for MSDs. ${ }^{27} \mathrm{~A}$ balance between illness and wellness has been described as significant for the overall experience of health among people with MSDs. ${ }^{28}{ }^{29}$ Including a well-being questionnaire may give information about health promoting aspects by capturing positive aspects of emotional functioning. Hence, in order to make the assessment of the emotional functioning domain more thorough, we decided to include the short form of the Ryff Psychological Well-being Scale (RPWS).22 23 30-33 


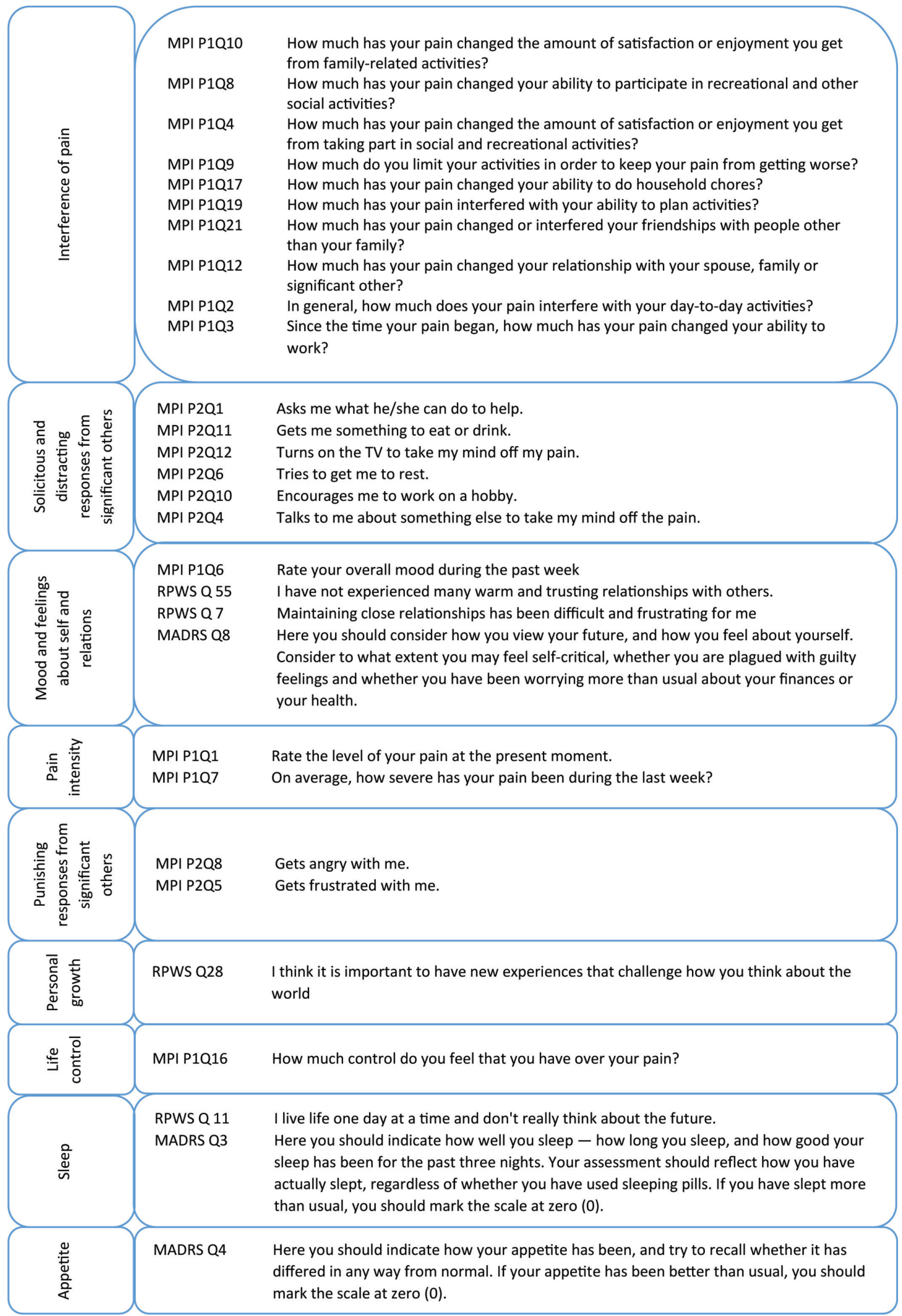

Figure 1 Previous model. MADRS-S, Montgomery Åsberg Depression Rating Scale; MPI-S, Multidimensional Pain Inventory; RPWS, Ryff's Psychological Well-being Scale. 


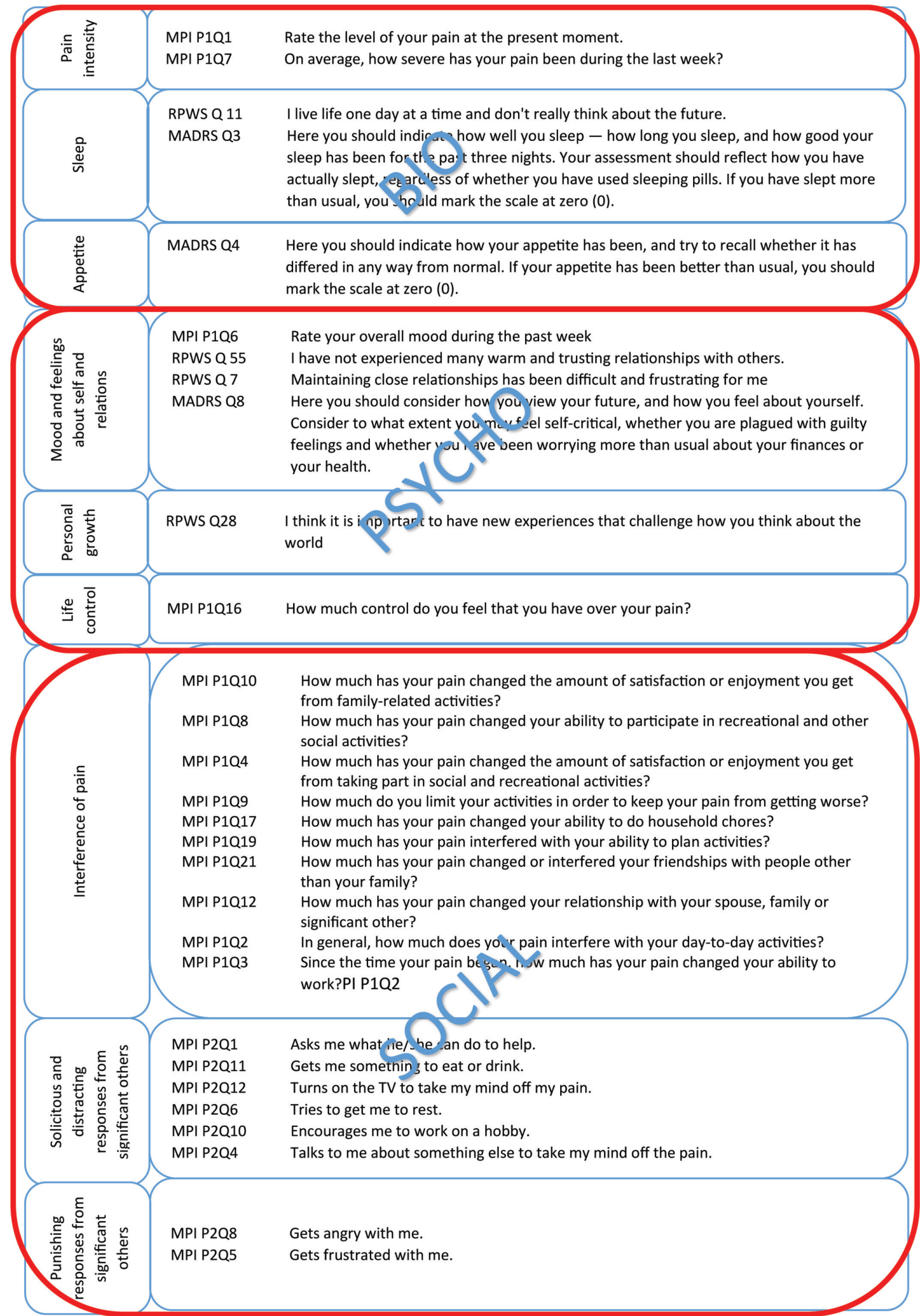

Figure 2 Model based on the biopsychosocial model. MADRS-S, Montgomery Åsberg Depression Rating Scale; MPI-S, Multidimensional Pain Inventory; RPWS, Ryff's Psychological Well-being Scale. 
A

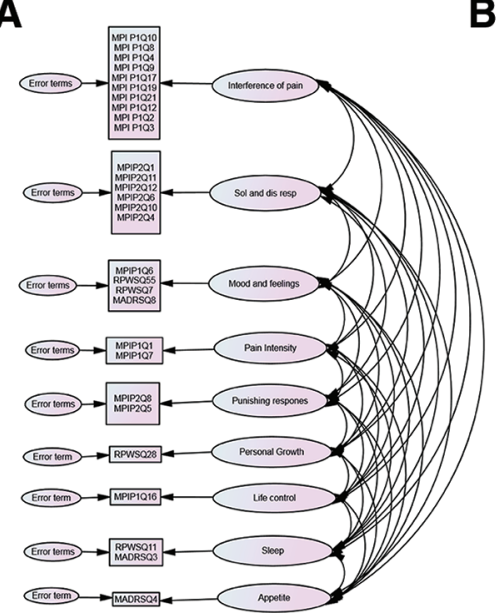

B

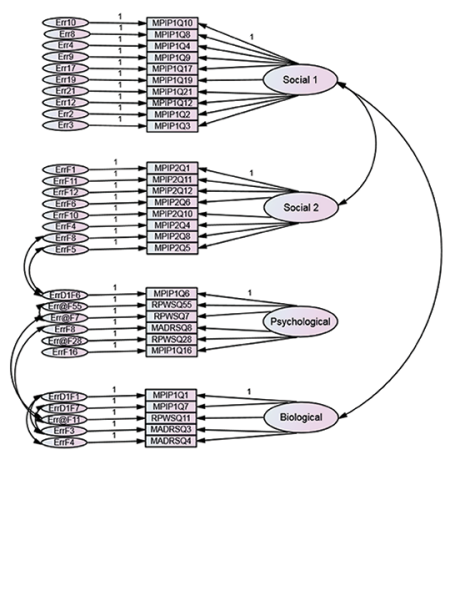

C

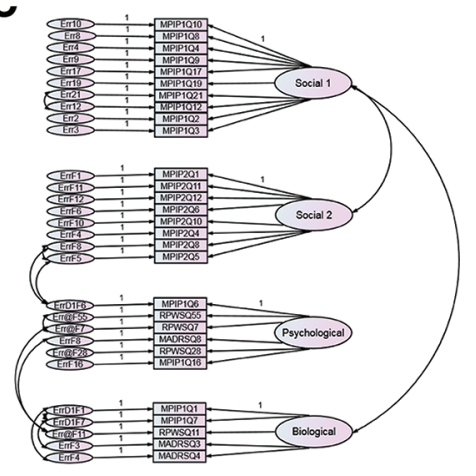

Figure 3 Graphical illustration of tested models by confirmatory factor analysis. From left: (A) Model 1; (B) Model 2; (C) Model 3. MADRS-S, Montgomery Åsberg Depression Rating Scale; MPI-S, Multidimensional Pain Inventory; RPWS, Ryff's Psychological Well-being Scale.

RPWS consists of 18 items, divided into six subscales with three items each: self-acceptance, positive relations with others, autonomy, environmental mastery, purpose in life and personal growth. ${ }^{31}$ The items are posed as statements, as 'I like most aspects of my personality' and the answers are given on a response scale between 1 (very strongly disagree) and 6 (very strongly agree). Some questions (numbers 7, 9, 11, 32, 42, 55, 65 and 76) have to be recoded so that high scores correspond to high wellbeing for all items.

\section{Statistical analyses}

IBM SPSS Statistics V.22.0 was used for descriptive statistics and explorative factor analysis (principal component analysis (PCA)), and IBM AMOS V.22.0 was used for CFA.

\section{Confirmatory factor analysis}

A CFA was conducted to assess the construct validity of the questionnaire. In all, we tested three models (figures 1, 2 and 3A-C). First, we tested a model with a factor structure consisting of nine factors and 29 items ${ }^{1}$ (figure 1). We then tested a model with a factor structure originated from a biopsychosocial approach to chronic pain $^{4}$ (figure 2). This model consists of four factors and the same 29 items as in the first model. Some of the four factors were allowed to correlate and even some of the error terms were allowed to correlate (figure 3B-C). In the sample of 116 participants, there were internal missing observations, that is, missing observations in parts of the questionnaire. Twenty-two participants had at least one missing observation of the included items. The models were estimated by the method of maximum likelihood (ML). The covariance matrix of the observed values of the items was the basis in the estimation process. ML estimation assumes items measured on a continuous scale and multivariate normality. Moreover, missing data must have a missing data pattern generated completely at random for ML estimates to be consistent and effective. When data are missing at random, ML estimates are unbiased and efficient as the sample size grows to be large. ML estimation (full information ML) in AMOS is considered to yield lesser biased estimates compared with other methods to handle missing data even if data are missing not at random. ${ }^{34}$ We also made the analysis of the models based on listwise deletion, that is, we deleted the 22 participants for which there were at least one missing observation on an item. The purpose of this was to be able to use modification indices and standardised residuals in AMOS to get indications of how to modify and refine the specification of the models. Moreover, we were also able to compare the estimates from listwise deletion with those based on the complete dataset. The main results are based on the complete dataset.

The measurements from the included items yield ordered categorical data. Therefore, we also made the estimation by Bayesian methods to compare the estimates and to evaluate estimation diagnostics. In AMOS, the approach to the analysis of ordered categorical data is by Bayesian method of estimation. ${ }^{34}$ Briefly, the Bayesian method of estimation produces a series of estimates of factor loadings, variances and covariances based on simulations by a Markov chain Monte Carlo (MCMC) algorithm. Thereby, we are able to study the distribution of the estimates and some summary measures of the simulation process to assess the statistical properties of the estimates.

In the specification of the models, we fixed one factor loading in each domain to one in order to set the scale for the unobserved factors. We allowed all the nine factors in the first model to correlate, and in the second and third model, we allowed some of the four factors to correlate according to the biopsychosocial model. Furthermore, we specified that some of the error terms correlated (see figure $3 \mathrm{~A}-\mathrm{C}$ ).

For the evaluation of the models as a whole, we primarily used some of the statistics of goodness of fit. We used Model Chi-square (CMIN), the ratio (CMIN/ 
Table 1 Reliability of the questionnaires $(n=116)$

\begin{tabular}{|c|c|c|c|c|}
\hline Questionnaire & Valid cases & Cronbach's $\alpha$ & Item means & $\begin{array}{l}\text { Range } \\
\text { (max - min) }\end{array}$ \\
\hline MPI-S-overall score & 82 & 0.81 & 3.2 & 4.1 \\
\hline MPI-S-interference & 88 & 0.92 & 3.8 & 2.5 \\
\hline MPI-S-life control & 115 & 0.77 & 3.2 & 0.76 \\
\hline MPI-S-responses from significant others: punishing & 103 & 0.86 & 1.3 & 0.60 \\
\hline MPI-S-responses from significant others: solicitous & 103 & 0.80 & 3.5 & 0.24 \\
\hline MPI-S-responses from significant others: distracting & 103 & 0.69 & 2.9 & 0.98 \\
\hline MADRS-S-overall score & 102 & 0.89 & 1.7 & 2.0 \\
\hline RPWS-positive relations & 114 & 0.59 & 4.4 & 0.89 \\
\hline RPWS-purpose in life & 114 & -0.10 & 4.4 & 1.3 \\
\hline RPWS-personal growth & 115 & 0.59 & 4.4 & 0.86 \\
\hline RPWS-autonomy & 115 & 0.61 & 4.3 & 0.42 \\
\hline
\end{tabular}

MADRS-S, Montgomery Åsberg Depression Rating Scale; MPI-S, Multidimensional Pain Inventory; RPWS, Ryff's Psychological Well-being Scale.

df), where CFI is the comparative fit index, the normed fit index (NFI), parsimony-adjusted normed fit index (PNFI) and root mean square error of approximation (RMSEA) with 90\% CIs. CMIN is a statistic of the closeness of the specified model in terms of estimated covariances and the observed covariances. A small value and a $\mathrm{p}$ value $>0.05$ indicate an acceptable model. The ratio of CMIN/df $<3$ is often used as a criterion for an acceptable model. Values for CFI and NFI range from 0 to 1 , and values $>0.9$ are indicative of good models and values $>0.95$ of excellent models. PNFI is based on NFI and penalise model complexity by adjusting for the $\mathrm{df}$. In conjunction with NFI values in the range 0.9 values as low as 0.5 could be accepted. Finally, acceptable values of RMSEA are $<0.06$. For discussion of which of the many goodness-of-fit indices to use and their cut-off values indicating well-fitted models, see, for example, studies by Byrne, $\mathrm{Hu}$ and Bentler, Hooper $e t$ al and Kääriäinen et $a l .{ }^{34-37}$ Our model evaluation also includes inspection of estimated parameters where we looked for reasonable size and sign of the factor loadings, variances and covariances and if they were statistically significant.

\section{Explorative factor analysis, PCA}

Initially, Cronbach's $\alpha$ was calculated to determine the internal consistency of the instruments' total and subscale scores (table 1).

Thereafter, explorative factor analysis was performed, using PCA for extraction and orthogonal varimax rotation with Kaiser normalisation to clarify factor structure.
A two-step procedure was chosen in the factor analysis to get an acceptable subject-to-variable ratio. Kaiser-MeyerOlkin measure of sampling adequacy (KMO) and Bartlett's test were used to determine the adequacy of performing a factor analysis on the selected data (table 2). The KMOs were acceptably above $0.70,{ }^{35}$ and Bartlett's test showed significant results for all three questionnaires $(p<0.05)$. An eigenvalue $>1$ and scree plot were used to determine the number of factors to extract, as recommended for PCA. $^{36}$ Two possible levels of factor loadings were considered throughout the analysis, $\geq 0.70$ and $\geq 0.60$. When selecting the level of factor loadings, coverage regarding included items in each factor and the logic of the final factor structure were judged.

In the first step of the explorative factor analysis, separate analyses were performed on the data from different questionnaires. The satisfactory factor loading was initially

\begin{tabular}{|c|c|c|}
\hline Questionnaire & $\begin{array}{l}\text { Kaiser-Meyer-Olkin } \\
\text { (KMO) }\end{array}$ & Bartlett* \\
\hline MPI-S & 0.785 & 0.000 \\
\hline MADRS-S & 0.869 & 0.000 \\
\hline RPWS & 0.893 & 0.000 \\
\hline
\end{tabular}

${ }^{*} \mathrm{P}<0.05$.

MADRS-S, Montgomery Åsberg Depression Rating Scale; MPI-S, Multidimensional Pain Inventory- Swedish version; RPWS, Ryff's Psychological Well-being Scale. 
Table 3 Goodness-of-fit statistics for confirmatory factor models estimated by ML ( $n=116)$

\begin{tabular}{llllllll}
\hline Model & CMIN & df & CMIN/df & CFI & NFI & PNFI & RMSEA (90\% CI) \\
\hline 1 & 706.60 & 350 & 2.019 & 0.763 & 0.636 & 0.512 & $0.094(0.084$ to 0.104$)$ \\
2 & 770.50 & 371 & 2.077 & 0.735 & 0.603 & 0.514 & $0.097(0.087$ to 0.106$)$ \\
3 & 670.96 & 368 & 1.823 & 0.799 & 0.654 & 0.554 & $0.085(0.074$ to 0.095$)$ \\
\hline
\end{tabular}

CFI, comparative fit index; CMIN, Model chi-square; ML, maximum likelihood; NFI, normed fit index; PNFI, parsimony- adjusted normed fit index; RMSEA, root mean square error of approximation.

decided to $\geq 0.7$. As there was absence of items in one factor for the MPI-S, when choosing factor loading $\geq 0.7$, we chose to set the factor loading to $\geq 0.6$ instead. Second, we performed a joint factor analysis including all items with a factor loading $\geq 0.6$ for MPI-S and RPWS. The MADRS-S was excluded as no rotated factor solution was attained in the separate factor analysis, not even after an analysis with exclusion of items with low values for communalities. The joint factor analysis of MPI-S and RPWS resulted in a factor solution with a KMO 0.699, but no rotated factor solution. Thus, we chose to do another joint factor analysis, this time including all items with a factor loading $\geq 0.7$, which resulted in a rotated factor solution including eight factors. The final factor solution was then compared with the result from our previous study. ${ }^{10}$

\section{RESULTS}

The sample consisted of 116 participants, male $(n=29)$ and female $(\mathrm{n}=87)$, with non-specific MSDs in different parts of the body as indicated on pain drawings (mean age 46 years; range 20-69; SD 10.2). The participants reported pain durations of at least 3 months (mean duration 132 months; range 6-576; SD 116.4). Twenty-seven percent of the participants were on sick leave at the time of the study. Nineteen percent of the participants were living alone, $5 \%$ were living alone with one or several children, $36 \%$ were living with another adult and $40 \%$ were living with another adult and one or several children.

\section{Confirmatory factor analysis}

The three models that are the result of the CFA are presented in figure 3A-C. The goodness-of-fit statistics for Models 1 to 3 are shown in table 3. Neither of the values of Model 1 and Model 2 were satisfactory to meet the criterion for an acceptable model. By means of analysis based on listwise deletion and use of modification indices and standardised residuals, we tested some correlations between residuals. In Model 2, eight correlations were specified and in Model 3 eleven (see figure 3B,C). Although the values of the goodness-of-fit statistics are somewhat better, they are not fully acceptable.

Table 4 shows the estimated factor loadings by ML and Bayesian method (see also figures 1 and 2 for item wordings and relation to factors). The factor loadings are all statistically significant, except 'MADRS Q3' in Model 1 and 'RPWS Q 11' in Models 2 and 3. Comparing the estimates of factor loadings from ML with the estimates from
Bayesian method shows some discrepancies. Some of the distributions of the simulated estimates showed skewness and kurtosis. Further diagnostics from the Bayesian method implies problems with convergence and thus

Table 4 Parameter estimates of factor loadings from CFA Models $1-3$ estimated by ML and Model 3 by Bayesian method

\begin{tabular}{|c|c|c|c|c|}
\hline $\begin{array}{l}\text { Parameters, } \\
\text { items }\end{array}$ & ML 1* & $M L 2^{*}$ & ML $3^{*}$ & Bayes ML 3† \\
\hline MPI P1Q10 & 1.000 & 1.000 & 1.000 & 1.000 \\
\hline MPI P1Q8 & 1.124 & 1.124 & 1.145 & 1.193 \\
\hline MPI P1Q4 & 1.190 & 1.187 & 1.199 & 1.246 \\
\hline MPI P1Q9 & 0.788 & 0.793 & 0.810 & 0.843 \\
\hline MPI P1Q17 & 0.953 & 0.958 & 0.973 & 1.015 \\
\hline MPI P1Q19 & 1.071 & 1.059 & 1.075 & 1.126 \\
\hline MPI P1Q21 & 1.319 & 1.307 & 1.274 & 1.327 \\
\hline MPI P1Q12 & 1.214 & 1.202 & 1.145 & 1.192 \\
\hline MPI P1Q2 & 0.909 & 0.903 & 0.927 & 0.965 \\
\hline MPI P1Q3 & 0.756 & 0.754 & 0.779 & 0.813 \\
\hline MPI P2Q1 & 1.000 & 1.000 & 1.000 & 1.000 \\
\hline MPI P2Q11 & 1.129 & 1.080 & 1.138 & 1.183 \\
\hline MPI P2Q12 & 0.938 & 0.900 & 0.926 & 0.967 \\
\hline MPI P2Q6 & 1.138 & 1.115 & 1.143 & 1.189 \\
\hline MPI P2Q10 & 1.537 & 1.563 & 1.523 & 1.581 \\
\hline MPI P2Q4 & 1.231 & 1.170 & 1.206 & 1.256 \\
\hline MPI P2Q8 & 1.000 & -0.492 & -0.370 & -0.378 \\
\hline MPI P2Q5 & 1.449 & -0.743 & -0.662 & -0.676 \\
\hline MPI P1Q6 & 1.000 & 1.000 & 1.000 & 1.000 \\
\hline RPWS Q55 & -1.103 & -0.664 & -0.664 & -0.641 \\
\hline RPWS Q7 & -1.016 & -0.490 & -0.489 & -0.464 \\
\hline MADRS Q8 & 0.914 & 1.116 & 1.112 & 1.097 \\
\hline RPWS Q28 & 1.000 & -0.503 & -0.503 & -0.496 \\
\hline MPI P1Q16 & 1.000 & -0.598 & -0.602 & -0.623 \\
\hline RPWS Q11 & 1.000 & -0.062 & -0.053 & -0.057 \\
\hline MADRS Q3 & -0.122 & 1.016 & 0.955 & 0.990 \\
\hline MADRS Q4 & 1.000 & 0.346 & 0.382 & 0.394 \\
\hline MPI P1Q1 & 1.000 & 1.000 & 1.000 & 1.000 \\
\hline MPI P1Q7 & 1.063 & 0.993 & 0.927 & 0.944 \\
\hline
\end{tabular}

Bold indicate non statistically significant loadings.

CFA, confirmatory factor analysis; MADRS-S, Montgomery

Åsberg Depression Rating Scale; ML, maximum likelihood; MPI-S, Multidimensional Pain Inventory; RPWS, Ryff's Psychological Wellbeing Scale. 
not stable or reliable parameter estimates. The MCMC sampling process started a thinning process to reduce the autocorrelation between successive samples (see the study by Arbuckle ${ }^{38}$ for a description).

The conclusion was that the models were not totally acceptable based on goodness-of-fit statistics and not feasible parameter estimates. That some of the problem may be caused from the ordered categorical data structure may not be ruled out based on the results from the Bayesian method.

In the separate explorative factor analysis (PCA) of MPI-S, eight factors were extracted that explained $72.6 \%$ of the variance, while the PCA of RPWS extracted five factors that explained $62.6 \%$ of the variance. In the PCA of MADRS-S, no rotated component matrix was attained. As the values for communalities were low for the items sleep and appetite (slightly above 200), these were excluded and a new PCA was run. Unfortunately, no rotated component was attained despite the removal of items.

In the joint PCA, all items $\geq 0.6$ for MPI-S and RPWS were chosen, as a level of $\geq 0.7$ left factor seven in MPI-S without any item. MADRS-S was not included in the joint PCA as no rotated component matrix was attained in the separate PCA. The joint PCA of MPI-S and RPWS including items with a factor loading $\geq 0.6$ did not produce any rotated component matrix; thus, another PCA including items with a factor loading $\geq 0.7$ of MPI-S and RPWS was performed. The result is presented in tables 5 and 6. This final PCA extracted an eight-factor solution, which explained $72.7 \%$ of the variance. Items and factor structure of the eight-factor solution including 16 items loading $\geq 0.70$ are shown in table 5 .

Factor 1 included four items from MPI-S concerning consequences in daily life and relations due to the pain (see table 5). Factor 2 included four items from MPI-S

Table 5 Rotated component matrix based on MPI and RPWS

\section{Rotated component matrix ${ }^{\star}$}

\begin{tabular}{|c|c|c|c|c|c|c|c|c|}
\hline & \multicolumn{8}{|c|}{ Component } \\
\hline & 1 & 2 & 3 & 4 & 5 & 6 & 7 & 8 \\
\hline $\begin{array}{l}\text { MPI P1Q10. How much has your pain changed the } \\
\text { amount of satisfaction or enjoyment you get from family- } \\
\text { related activities? }\end{array}$ & 0.880 & -0.070 & -0.116 & 0.177 & 0.050 & -0.071 & 0.002 & 0.042 \\
\hline $\begin{array}{l}\text { MPI P1Q8. How much has your pain changed your ability } \\
\text { to participate in recreational and other social activities? }\end{array}$ & 0.876 & 0.014 & -0.094 & 0.213 & -0.007 & -0.041 & -0.102 & -0.006 \\
\hline $\begin{array}{l}\text { MPI P1Q21. How much has your pain changed or } \\
\text { interfered your friendships with people other than your } \\
\text { family? }\end{array}$ & 0.804 & -0.188 & -0.094 & 0.024 & 0.089 & 0.010 & 0.015 & 0.180 \\
\hline $\begin{array}{l}\text { MPI P1Q5 How much support or help do you get from } \\
\text { your family or others related when you are in pain? }\end{array}$ & -0.037 & 0.787 & 0.289 & 0.181 & 0.143 & -0.018 & 0.051 & 0.101 \\
\hline MPI P2Q1. Asks me what he/she can do to help. & 0.122 & 0.702 & 0.154 & 0.203 & 0.096 & -0.137 & 0.008 & 0.257 \\
\hline $\begin{array}{l}\text { RPWS Q3 I am quite good at managing the many } \\
\text { responsibilities of my daily life }\end{array}$ & -0.212 & 0.197 & 0.762 & -0.015 & -0.054 & 0.172 & 0.078 & 0.033 \\
\hline $\begin{array}{l}\text { MPI P1Q1. Rate the level of your pain at the present } \\
\text { moment. }\end{array}$ & 0.260 & 0.128 & -0.102 & 0.851 & 0.063 & 0.046 & 0.075 & -0.014 \\
\hline $\begin{array}{l}\text { MPI P1Q7. On average, how severe has your pain been } \\
\text { during the last week? }\end{array}$ & 0.239 & 0.036 & 0.025 & 0.868 & 0.092 & -0.060 & -0.124 & -0.003 \\
\hline MPI P2Q9. Gets me pain medication. & 0.023 & 0.122 & -0.094 & 0.061 & 0.776 & 0.202 & -0.047 & 0.184 \\
\hline $\begin{array}{l}\text { MPI P2Q12. Turns on the TV to take my mind off my } \\
\text { pain. }\end{array}$ & 0.095 & 0.257 & -0.116 & 0.111 & 0.755 & -0.040 & 0.190 & 0.018 \\
\hline $\begin{array}{l}\text { RPWS Q } 11 \text {. I live life } 1 \text { day at a time and don't really } \\
\text { think about the future. }\end{array}$ & -0.002 & -0.214 & 0.171 & 0.001 & 0.127 & 0.811 & -0.074 & -0.056 \\
\hline
\end{tabular}

Extraction method: principal component analysis. Rotation method: varimax with Kaiser normalisation.

Bold figures are selected items with factor loading above 0.7. *Rotation converged in 12 iterations.

MPI-S, Multidimensional Pain Inventory ; RPWS, Ryff's Psychological Well-being Scale. 
Table 6 Total variance explained

Total variance explained

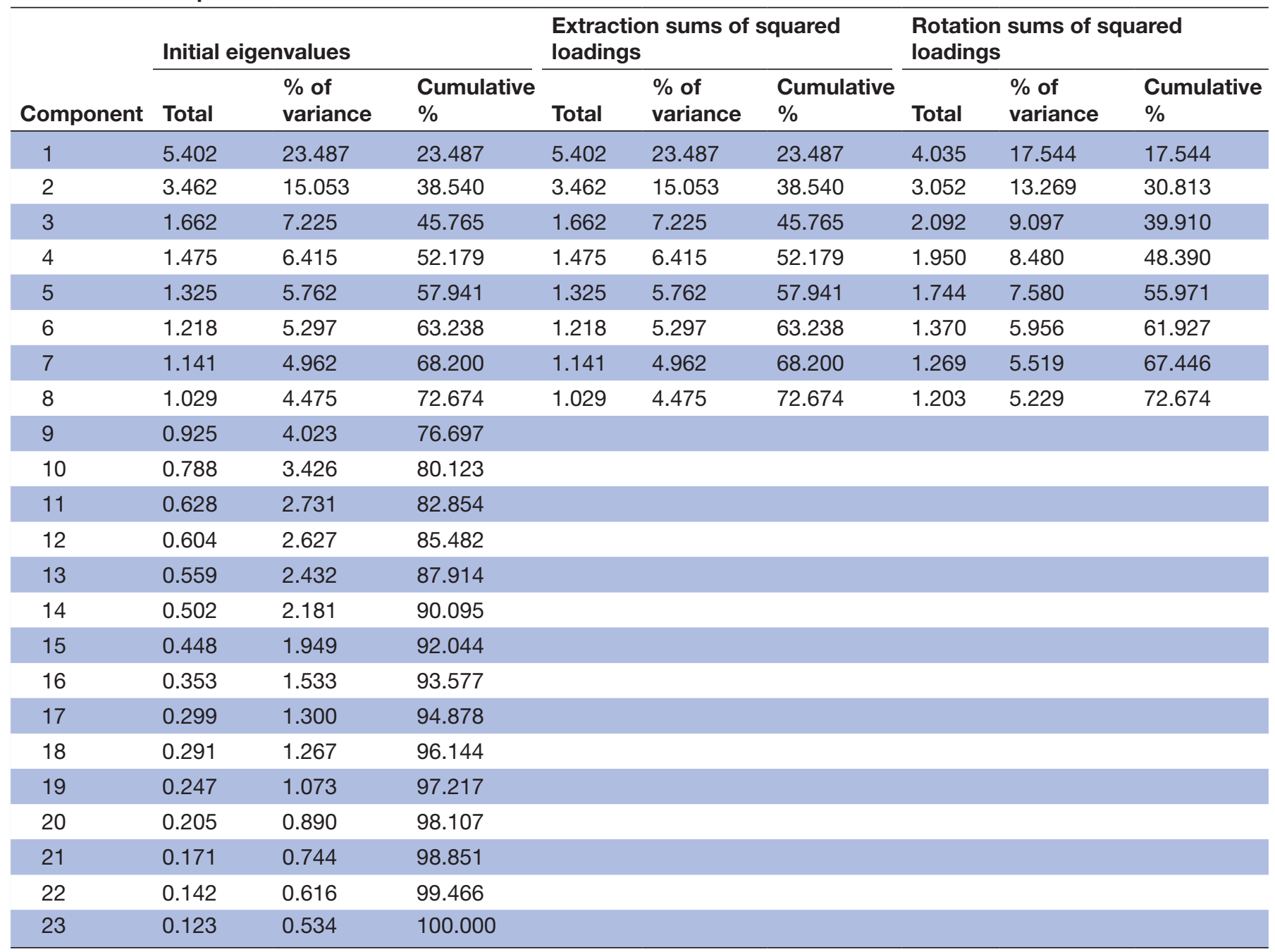

Extraction method: principal component analysis.

regarding solicitous and distracting and punishing responses from significant others. Factor 3 included one item on life control from RPWS. Factor 4 included two items regarding pain intensity. Factor 5 included two items from MPI-S about solicitous and distracting responses from significant others. Factor 6 included one item from RPWS on life control, as did also factor 7. Factor 8 included one item about solicitous and distracting responses from significant others.

A visual comparison was performed between the factor structure attained in this last joint PCA (see table 5) and the results attained in our previous study with a similar aim and design ${ }^{10}$ (see figure 1). The results show that 11 items were similar between the two models, while some items only were included in either the new or the old model. Comparing the new model (table 5) with previous (figure 1), all four items included in factor 1 , and the four in factor 2, were included in previous study. The single item in factor 3 was not included in previous model. The two items in factor 4 were also included in previous model, while one of the two items in factor 5 was included. The three single items in factors 6,7 and 8 were not included in previous model. Starting comparison in the previous model (figure 1), six items from MPI-S were not included in factor 1 in the present model (table 5). Three items from MPI-S were not included in factor 2. None of the four items from MPI-S, RPWS and MADRS-S were included in the present model, while both the two items from MPI-S in factor 4 and the two in factor 5 were included. None of the items from factors 6 to 9 was included in the present model.

\section{DISCUSSION}

The main findings of the present study are that the CFA not ended up in a model with acceptable validity, neither when the analysis was based on a model from a previous study nor when it was based on a model inspired by the biopsychosocial model. The second step in the analysis, the exploratory factor analysis, resulted in a 
factor solution only partly corresponding to the previously suggested short-form questionnaire. ${ }^{10}$ The results of the present study do not support the suitability of the suggested short-form questionnaire for evaluation of symptoms among men and women with non-specific MSDs in any part of the body.

Looking at the items that corresponded to the exploratory factor analysis, all items concerning pain intensity, interference of pain and solicitous/punishing responses from significant others included in the present model were also included in the previously suggested short-form questionnaire. ${ }^{10}$ For one factor (5), one of the two items was similar. For the rest of the factors, none of the items was included in the results of the previous exploratory factor analysis. One explanation to the differences between the final exploratory factor analysis in the present study and previous is to find in the results of the separate factor analyses. In the present study, no rotated factor structure was attained for MADRS-S, why no items from this questionnaire are included in the final factor structure.

What could be the cause to such a different result of the explorative factor analysis compared with our previous study ${ }^{10}$ ? One explanation can be differences between the two samples. The sample in previous study ${ }^{10}$ included women with non-specific MSDs in the neck/shoulder, while the present included women and men, and non-specific MSDs in any part of the body. The previous study also had a strict schedule of criteria for exclusion, as, for example, low-back pain, previous trauma, rheumatic, inflammatory or neurological disease or fibromyalgia (for details on study protocol, see ISRCTN trial registration number 92199001 at https://www.isrctn.com). The sampling procedure also differed, in that the participants in previous study were recruited via advertising in local papers. A weakness of the present study is the rather small sample, and in addition to this some internal missing data. Several rules of thumb are presented regarding sufficient sample sizes for factor analyses. Subject-to-variable ratios of $4: 1$ or $5: 1$ or a sample size of 100 or 200 people are among those. ${ }^{39}$ Another approach is to determine the stability of a factor solution by determining component saturation (primarily size of factor loadings; second number of items) in combination to total sample size. ${ }^{40}$ Stable factor solutions can, according to this second approach, be attained using samples as small as 50 with factor loadings at $0.80 .^{40}$ Sample sizes of 150 and factor loading of 0.60 may also produce stable factor solutions and if four or more items have a factor loading of 0.60 on each component the sample size may even be smaller. ${ }^{40}$

Yet, another circumstance that may lead to inconsistent results was analysing ordinal data as they were normally distributed. To circumvent this potential problem, we applied Bayesian estimation to compare those results with the ML results in the CFA. There were some discrepancies and indications of lack of convergence. This may be interpreted as that part of the problems with unacceptable goodness-of-fit values may be caused from the ordered categorical data structure in the estimation procedure.
Small sample sizes are a common problem when collecting questionnaire data. Collecting data in this group probably adds to the problem, as difficulty concentrating seem to be part of the symptoms in this group, ${ }^{9}$ especially as our study required answering several questionnaires. An effort we made to increase the sample size was to ask the personnel to inform the participants regarding the study and the possible benefits for future patients and offer time during the rehabilitation sessions to fill out the questionnaires.

The amount of missing cases in the inclusion of participants is not possible to establish, as participation built on voluntary inclusion, not distribution of a certain number of questionnaires to a specific, selected group. However, we also had missing values for some of the participants. Under the assumption that the missing data process was missing at random, the estimation methods produce efficient and consistent estimates of factor loadings in the CFA. There is, although, a possibility that the missing data process is not at random yielding biased estimates.

IMMPACT recommendations seem sound in including pain intensity, physical function, emotional function and general improvement in assessment of MSDs.${ }^{13}$ Including relevant aspects, representing the biopsychosocial aspects that often are affected for a person with $\mathrm{MSDs}^{41}$ when constructing a short-form questionnaire is considered a strength of the present study. However, the recommendation of questionnaires to use might need reconsidering. IMMPACT have recently published recommendations regarding the assessment of physical function and participation in chronic pain, taking the WHO's International Classification of Function and Health (ICF) in to consideration. ${ }^{42}$ Unfortunately, these IMMPACT recommendations does not include a thorough analysis of the content and quality of the recommended questionnaires. In the last decade, a development regarding evaluation of questionnaires has taken place. For example, several reviews regarding the content and/or quality of questionnaires for assessment of physical function have been published. ${ }^{43-45}$ Starting by choosing high-quality questionnaires for the recommended dimensions based on reviews of content and quality could be a possible way to finally end up with a high-quality short-form questionnaire. Another vital aspect is also to attain a larger sample to get a more reliable result of the psychometric tests. One question still rendering answer is whether one shortform questionnaire is possible for measurement of symptoms in all sorts of MSDs or if there is a need to develop specific questionnaires for different MSDs such as neck pain and low back pain.

\section{CONCLUSION}

There is a multitude of different questionnaires that are used in different combinations. Our intention was to create a short questionnaire that combines relevant aspects to measure in this group of patients. By selecting these and combining them into one short questionnaire, 
the intention was to contribute to a reduction of the use of a multitude of questionnaires and combinations of them and to hopefully increase the comparability between the results of different studies. However, neither the CFA nor the exploratory ended up in an acceptable model; thereby, the results of the present study do not support the suitability of the suggested short-form questionnaire for evaluation of symptoms among men and women with non-specific MSDs in any part of the body. To draw any final conclusions regarding the usefulness of this questionnaire in different samples, as well as among women with neck pain, further studies are required.

\section{Patient and public involvement}

Patient and public were not involved in the design or analysis of the study. Patients and staff were involved in data collection, as the staff presented the study and provided questionnaires, while the patients answered the questionnaires.

\section{Author affiliations}

${ }^{1}$ Centre for Musculoskeletal Research, Department of Occupational and Public Health Sciences, Faculty of Occupational and Health Studies, University of Gävle, Gävle, Sweden

${ }^{2}$ Centre for Research \& Development, Uppsala University/Region Gävleborg, Gävle, Sweden

${ }^{3}$ Department of Health and Caring Sciences, Faculty of Occupational and Health Studies, University of Gävle, Gävle, Sweden

${ }^{4}$ Department of Public Health and Caring Sciences, Faculty of Medicine, Uppsala University, Uppsala, Sweden

Acknowledgements The authors are grateful to all the staff working in the rehabilitation teams for helping us to inform the patients about the study, distribute and collect questionnaires. We are also grateful to all participants in the multimodal rehabilitation who were willing to participate in the study.

Contributors BW, DR, $\mathrm{HH}$ and AN all contributed to the design of the study. BW, DR and $\mathrm{AN}$ performed the data collection. BW and $\mathrm{HH}$ made the statistical analyses, while BW made the visual comparison between the results of present and previous statistical analyses. All authors contributed to the interpretation of the results, writing, reading and revising the manuscript.

Funding The authors have not declared a specific grant for this research from any funding agency in the public, commercial or not-for-profit sectors.

Competing interests None declared.

Patient consent for publication Obtained.

Ethics approval The study was approved by the regional ethical review board in Uppsala, Sweden (D-nr. 2010-116).

Provenance and peer review Not commissioned; externally peer reviewed.

Data sharing statement No additional data are available.

Open access This is an open access article distributed in accordance with the Creative Commons Attribution Non Commercial (CC BY-NC 4.0) license, which permits others to distribute, remix, adapt, build upon this work non-commercially, and license their derivative works on different terms, provided the original work is properly cited, appropriate credit is given, any changes made indicated, and the use is non-commercial. See: http://creativecommons.org/licenses/by-nc/4.0/.

\section{REFERENCES}

1. Hubertsson J, Englund M, Hallgårde U, et al. Sick leave patterns in common musculoskeletal disorders--a study of doctor prescribed sick leave. BMC Musculoskelet Disord 2014;15:176.

2. McDonald M, DiBonaventura M, Ullman S. Musculoskeletal pain in the workforce: the effects of back, arthritis, and fibromyalgia pain on quality of life and work productivity. $J$ Occup Environ Med 2011:53:765-70.

3. Bongers PM, ljmker S, van den Heuvel S, et al. Epidemiology of work related neck and upper limb problems: Psychosocial and personal risk factors (Part I) and effective interventions from a bio behavioural perspective (Part II). J Occup Rehabil 2006;16:272-95.

4. Gatchel RJ, Peng YB, Peters ML, et al. The biopsychosocial approach to chronic pain: scientific advances and future directions. Psychol Bull 2007;133:581-624.

5. SBU. Methods for long term pain treatment (In Swedish). Stockholm: The Swedish Council onTechnology Assessment in Health Care, 2006.

6. SBU. Rehabilitation of patients with chronic pain conditions (In Swedish). Stockholm, 2010. no. SBU report no 198.

7. Kamper SJ, Apeldoorn AT, Chiarotto A, et al. Multidisciplinary biopsychosocial rehabilitation for chronic low back pain. Cochrane Database Syst Rev 2014:CD000963.

8. Turk DC, Dworkin RH, Allen RR, et al. Core outcome domains for chronic pain clinical trials: IMMPACT recommendations. Pain 2003;106:337-45.

9 Wiitavaara B, Björklund M, Brulin C, et al. How well do questionnaires on symptoms in neck-shoulder disorders capture the experiences of those who suffer from neck-shoulder disorders? A content analysis of questionnaires and interviews. BMC Musculoskelet Disord 2009;10:10.

10. Wiitavaara B, Björklund M, Nilsson A. An initial factor analysis of prominent aspects of health experiences for women with neckshoulder pain. Disabil Rehabil 2012;34:934-42.

11. Dworkin RH, Turk DC, Farrar JT, et al. Core outcome measures for chronic pain clinical trials: IMMPACT recommendations. Pain 2005;113:9-19.

12. Socialstyrelsen. Nationella indikationer för multimodal rehabilitering (National indications for multimodal rehabilitation) (In Swedish). https://www.socialstyrelsen.se/./nationella-indikationer-multimodalrehabilitering.pdf (cited 27 Nov 2017).

13. Dworkin RH, Turk DC, Wyrwich KW, et al. Interpreting the clinical importance of treatment outcomes in chronic pain clinical trials: IMMPACT recommendations. J Pain 2008;9:105-21.

14. Cleeland CS, Ryan KM. Pain assessment: global use of the Brief Pain Inventory. Ann Acad Med Singapore 1994;23:129-38.

15. Kerns RD, Turk DC, Rudy TE. The West Haven-Yale Multidimensional Pain Inventory (WHYMPI). Pain 1985;23:345-56.

16. Beck AT, Ward $\mathrm{CH}$, Mendelson $\mathrm{M}$, et al. An inventory for measuring depression. Arch Gen Psychiatry 1961;4:561-71.

17. Beck AT, Steer RA. Beck depression inventory. San Antonio,TX: Psychological Corporation, 1993.

18. McNair DM, Lorr M, Droppleman LF. Profile of Mood States (POMS) Manual. San Diego, CA: Educational and Industrial Testing Service, 1992.

19. Bergström KG, Jensen IB, Linton SJ, et al. A psychometric evaluation of the Swedish version of the Multidimensional Pain Inventory (MPI-S): a gender differentiated evaluation. Eur J Pain 1999;3:261-73.

20. Svanborg P, Asberg M. A new self-rating scale for depression and anxiety states based on the Comprehensive Psychopathological Rating Scale. Acta Psychiatr Scand 1994;89:21-8.

21. Svanborg P, Asberg M. A comparison between the Beck Depression Inventory (BDI) and the self-rating version of the Montgomery Asberg Depression Rating Scale (MADRS). J Affect Disord 2001;64:203-16.

22. Ryff CD, Singer BH, Dienberg Love G. Positive health: connecting well-being with biology. Philos Trans $R$ Soc Lond B Biol Sci 2004;359:1383-94.

23. Ryff CD, Dienberg Love G, Urry HL, et al. Psychological well-being and ill-being: do they have distinct or mirrored biological correlates? Psychother Psychosom 2006;75:85-95.

24. Fredrickson BL. The broaden-and-build theory of positive emotions. Philos Trans R Soc Lond B Biol Sci 2004;359:1367-77.

25. Lindfors $P$, Lundberg $U$. Is low cortisol release an indicator of positive health? Stress and Health 2002;18:153-60.

26. Turk DC, Dworkin RH, Revicki D, et al. Identifying important outcome domains for chronic pain clinical trials: an IMMPACT survey of people with pain. Pain 2008;137:276-85.

27. van der Windt $D$, Croft $P$, Penninx $B$. Neck and upper limb pain: more pain is associated with psychological distress and consultation rate in primary care. $J$ Rheumatol 2002;29:564-9.

28. Wiitavaara B, Lundman B, Barnekow-Bergkvist M, et al. Striking a balance--health experiences of male ambulance personnel with musculoskeletal symptoms: a grounded theory. Int J Nurs Stud 2007;44:770-9. 
29. Wiitavaara B, Barnekow-Bergkvist M, Brulin C. Striving for balance: a grounded theory study of health experiences of nurses with musculoskeletal problems. Int J Nurs Stud 2007;44:1379-90.

30. Ryff CD. Happiness is everything, or is it? Explorations on the meaning of psychological well-being. J Pers Soc Psychol 1989;57:1069-81.

31. Ryff CD. In the eye of the beholder: views of psychological wellbeing among middle-aged and older adults. Psychol Aging 1989;4:195-210.

32. Ryff CD, Singer B. The contours of positive human health. Psychol Inq 1998;9:1-28.

33. Lindfors P, Berntsson L, Lundberg U. Factor structure of Ryff's psychological well-being scales in Swedish female and male whitecollar workers. Pers Individ Dif 2006;40:1213-22.

34. Byrne B. Structural equation modeling with AMOS: basic concepts, applications, and programming. 2nd ed. New York: Routledge, Taylor \& Francis Group, 2010.

35. Hu L, Bentler P. Cutoff criteria for fit indexes in covariance structure analysis: Conventional criteria versus new alternatives: Structural Equation Modeling, 1999:1-55.

36. Hooper D, Coughlan J, Mullen M. Structural equation modelling: Guidelines for determining model fit. Electronic Journal of Business Research Methods 2008:6:53-60.

37. Kääriäinen $M$, Kanste $O$, Elo $S$, et al. Testing and verifying nursing theory by confirmatory factor analysis. J Adv Nurs 2011;67:1163-72.
38. Arbuckle JL. IBM® Amos TM 23 User's Guide. Chicago: Amos Development Corporation, 2014.

39. Streiner DL. Figuring out factors: the use and misuse of factor analysis. Can J Psychiatry 1994;39:135-40.

40. Floyd FJ, Widaman KF. Factor analysis in the development and refinement of clinical assessment instruments. Psychol Assess 1995;7:286-99.

41. Gatchel RJ. Comorbidity of chronic pain and mental health disorders: the biopsychosocial perspective. Am Psychol 2004;59:795-805.

42. Taylor AM, Phillips K, Patel KV, et al. Assessment of physical function and participation in chronic pain clinical trials: IMMPACT/OMERACT recommendations. Pain 2016;157:1836-50.

43. Ferreira ML, Borges BM, Rezende IL, et al. Are neck pain scales and questionnaires compatible with the international classification of functioning, disability and health? A systematic review. Disabil Rehabil 2010;32:1539-46.

44. Wiitavaara B, Heiden M. Content and psychometric evaluations of questionnaires for assessing physical function in people with neck disorders: a systematic review of the literature. Disabil Rehabil 2018;40:2227-35.

45. Schellingerhout JM, Verhagen AP, Heymans MW, et al. Measurement properties of disease-specific questionnaires in patients with neck pain: a systematic review. Qual Life Res 2012;21:659-70. 